\title{
Single Dose Versus Two Doses of Betamethasone for Lung Maturation in Preterm Rabbits
}

\author{
BO SUN, ALAN JOBE, EVELYN RIDER, AND MACHIKO IKEGAMI \\ Perinatal Research, Harbor-UCLA Medical Center, UCLA School of Medicine, Torrance, California 90509
}

\begin{abstract}
Most previous studies of induced lung maturation have used fetal exposures to multiple doses of hormones, and such treatments are associated with fetal growth retardation in rodents and rabbits. This study was designed to evaluate whether single-dose maternal corticosteroid treatments could induce lung maturation without causing fetal growth retardation. Lung maturation was evaluated in 27-d gestational age rabbits by measurements of lung function after preterm delivery and ventilation. Lung function was assessed by measurements of ventilatory requirements, responses to exogenous surfactant, measurements of the recovery of intravascular albumin in the lungs, and surfactant pool sizes. As demonstrated previously, 0.1 $\mathrm{mg} / \mathrm{kg}$ betamethasone $(1 \mathrm{mg}=2.13 \mu \mathrm{mol}$ betamethasone $)$ given 48 and $24 \mathrm{~h}$ before delivery caused both growth retardation (birth weight $\mathbf{2 0 \%}$ lower than controls, $p<$ 0.01 ) and lung maturation (improved compliance, decreased radiolabeled albumin recoveries) despite lower alveolar saturated phosphatidylcholine pool sizes $(p<0.05$ versus controls). A single dose of $0.2 \mathrm{mg} / \mathrm{kg}$ betamethasone given $48 \mathrm{~h}$ before delivery had an equivalent effect on birth weight as the divided doses of $0.1 \mathrm{mg} / \mathrm{kg}$ betamethasone, with the only lung maturational effect being a decrease in recovery of labeled albumin in alveolar washes $(p<0.01)$. A single dose of $0.1 \mathrm{mg} / \mathrm{kg}$ betamethasone given $48 \mathrm{~h}$ before delivery decreased birth weight by $9.4 \%(p<0.01$ versus control) but had no effect on any of the lung maturation indicators. Fetal lung maturation caused by maternal corticosteroid is associated with global fetal growth retardation, and a single low dose of corticosteroid can cause growth retardation without inducing lung maturation. The induction of lung maturation with maternal corticosteroid does not result from an isolated effect of the hormone on the fetal lung. (Pediatr Res 33: 256-260, 1993)
\end{abstract}

\section{Abbreviations}

SatPC, saturated phosphatidylcholine

Beta, betamethasone as Celestone Soluspan

Corticosteroids are routinely used to induce lung maturation in fetuses at risk of preterm delivery, a clinical practice based on sound clinical trials (1). Liggins' initial description of induced lung maturation in fetal sheep resulted from studies using corticosteroid infusions (2). Most of the early experimental studies in sheep and rabbits used direct fetal injections of corticosteroids to evaluate maturation responses (3-5), whereas subsequent studies have generally used maternal treatments in rodents $(6,7)$, rabbits

Received July 20, 1992; accepted October 14, 1992.

Correspondence: Alan H. Jobe, M.D., Ph.D., Harbor-UCLA Medical Center. 1000 W. Carson Street, RB-1. Torrance, CA 90509.

Supported by National Institute of Child Health and Human Development Grant HD-20618.
(8), and monkeys (9) and continuous fetal infusions in sheep $(10-12)$. In the experimental studies and in clinical practice, multiple dosing schedules have been generally used $(1,13)$. However, single doses of maternal corticosteroids for intervals as short as $24 \mathrm{~h}$ were shown to induce surfactant proteins $(14,15)$ and to induce lung choline-phosphate cytidyltransferase and the adenylate cyclase system in fetal rats $(16,17)$. A uniform observation in rodents is that maternal corticosteroids also cause fetal growth retardation (18). We previously studied the hormone dose-lung maturation response relationship of two doses of corticosteroids given 48 and $24 \mathrm{~h}$ before delivery at $27 \mathrm{~d}$ gestational age in rabbits and found similar maturation responses with doses between 0.05 and $0.4 \mathrm{mg} / \mathrm{kg}(8)$. There were no maturational effects at doses of $0.03 \mathrm{mg} / \mathrm{kg}$ and below (19). In those studies, the lung maturation responses occurred only at corticosteroid doses that also caused fetal growth retardation in the rabbit $(8,19)$. In the present studies, we asked the following questions: Would a single dose of betamethasone be as effective as the multiple-dose schedule, and could lung maturation occur without growth retardation? Functional lung maturation was evaluated after delivery of the preterm rabbits, which were ventilated to permit the assessment of several maturational responses $(8,20)$. Surfactant treatments also were used to test if corticosteroid effects could be detected in lungs made surfactant-sufficient (20).

\section{MATERIALS AND METHODS}

Corticosteroid dosing. Time-mated pregnant rabbits were randomized to four groups and treated with intramuscular betamethasone (Celestone Soluspan, Schering Corp., Kenilworth, $\mathrm{NJ}$ ) or vehicle control according to the schedule in Table 1 . The Beta $0.1 \times 2$ group was selected as the two-dose corticosteroid treatment regimen because the dose was relatively low and known to consistently induce a number of maturational responses in fetal rabbits without causing excessive fetal loss (8, 20). The two single-dose schedules were selected to give either the same total dose or one half the dose received by the Beta 0.1 $\times 2$ comparison group.

Animal delivery and ventilation. The protocols were reviewed

Table 1. Corticosteroid dosing schedule

\begin{tabular}{lcc}
\hline Study group & Number of litters & Dosing schedule \\
\hline Control & 4 & $\begin{array}{c}\text { Vehicle- } 48 \mathrm{~h} \text { before de- } \\
\text { livery }\end{array}$ \\
Beta $0.1 \times 2$ & 4 & $0.1 \mathrm{mg} / \mathrm{kg}$ betamethasone* \\
& & $48 \mathrm{and} 24 \mathrm{~h}$ before de- \\
livery
\end{tabular}

* One mg betamethasone as Celestone Soluspan is equivalent to 2.13 $\mu \mathrm{mol}$ betamethasone. 
and approved by the Animal Care Committee at Harbor-UCLA Medical Center. Pregnant New Zealand White rabbits of known date mating to $\pm 2 \mathrm{~h}$ were lightly anesthetized by a slow intravesicular infusion of pentobarbital to effect followed by spinal anesthesia using $2 \mathrm{~mL}$ of $2 \%$ lidocaine: $0.5 \%$ bupivacaine (1:1, vol:vol). The rabbits received oxygen via a plastic bag gently secured around the neck. The uterus was exposed, and preterm rabbits at $27 \mathrm{~d}$ gestational age were sequentially delivered and given $0.1 \mathrm{mg} / \mathrm{kg}$ acepromazine and $10 \mathrm{mg} / \mathrm{kg}$ ketamine by intraperitoneal injection. A tracheal tube made from an 18-gauge stainless steel needle was tied into the trachea of each rabbit.

Every other rabbit in each litter received natural sheep surfactant at a weight-adjusted dose of $100 \mathrm{mg} / \mathrm{kg}$ lipid. This surfactant was recovered as previously described from the lung lavage of adult sheep (21). Each rabbit was ventilated with five breaths of $100 \% \mathrm{O}_{2}$ using an anesthesia bag with just enough pressure to visibly move the chest. The rabbits then were moved to $37^{\circ} \mathrm{C}$ temperature-controlled ventilator-plethysmography systems that permitted the simultaneous measurement of ventilator pressures and integrated tidal volumes for each rabbit $(22,23)$. The target tidal volumes were $8-9 \mathrm{~mL} / \mathrm{kg}$. The peak inspiratory pressures were individually adjusted to achieve the desired tidal volumes approximately every $5 \mathrm{~min}$ during the $30 \mathrm{~min}$ of ventilation. The other ventilator variables were held constant at a rate of 30 breaths/min, an inspiratory time of $1 \mathrm{~s}$, a positive end expiratory pressure of $3 \mathrm{~cm} \mathrm{H} \mathrm{H}_{2} \mathrm{O}$, and $100 \%$ oxygen. Immediately after the initiation of ventilation, the rabbits were given an external jugular vein injection of $0.2 \mathrm{~mL} 0.9 \% \mathrm{NaCl}$ containing $1 \mu \mathrm{Ci}^{125}$ I-labeled albumin to label the intravascular albumin (22). Each rabbit was ventilated for $30 \mathrm{~min}$, the endotracheal tube was obstructed, and the rabbit was killed with intrathecal lidocaine. After opening the chest, a blood sample was drawn from the heart for measurements of $\mathrm{PCO}_{2}, \mathrm{pH}, \mathrm{Hb}$, and radioactivity.

Processing of lungs. The rabbits then had standardized lung lavages repeated 5 times with $0.9 \% \mathrm{NaCl}$, and the lavages were pooled for each animal (8). The volumes were recorded and the amount of labeled albumin in each lavage was measured. The lavaged lungs were removed and weighed, and the amount of labeled albumin in the lungs was measured. The lungs then were homogenized in $0.9 \% \mathrm{NaCl}$, and an aliquot clarified by centrifugation was used for an $\mathrm{Hb}$ measurement with Drabkin's solution (24). The amount of labeled albumin retained in the lungs was corrected for the amount of blood-associated label to yield a value for the lung tissue alone.

Lipids from aliquots of the alveolar washes and lung homogenates were extracted with chloroform:methanol (2:1) and dried under nitrogen at $50^{\circ} \mathrm{C}$. The lipid extracts were treated with osmium tetroxide, and SatPC was recovered by neutral alumina column chromatography according to Mason et al. (25). SatPC was quantified by phosphorus assay according to Bartlett (26).

Data analysis. Statistical comparisons across the treatment groups were by analysis of variance with the Student-NeumanKeuls post-hoc test used to identify significant differences. Significance was accepted at $p<0.05$.

\section{RESULTS}

Description of animals. The two groups of newborn rabbits exposed to a total dose of $0.2 \mathrm{mg} / \mathrm{kg}$ betamethasone had the same $20 \%$ decrease in body weight relative to the control rabbits $(p<0.01)$ (Table 2$)$. Thus, the single- versus two-dose schedule had no differential effect on the growth retardation. The Beta $0.1 \times 1$ group was on average $9.4 \%$ lighter than the control group $(p<0.01)$ and $13 \%$ heavier than either of the two $0.2 \mathrm{mg} / \mathrm{kg}$ total dose groups $(p<0.01)$. Thus, the single lower dose of betamethasone resulted in less growth retardation.

Ventilation outcomes. The ventilation strategy was successful in that the animals received comparable tidal volumes of about $8 \mathrm{~mL} / \mathrm{kg}$ that resulted in similar $\mathrm{PCO}_{2}$ and $\mathrm{pH}$ values at $30 \mathrm{~min}$ of age. Ventilatory pressure requirements (peak inspiratory mi- nus positive and expiratory pressures) to achieve the tidal volumes were $21.2 \pm 2.7 \mathrm{~cm} \mathrm{H} \mathrm{H}_{2} \mathrm{O}$ (mean $\pm \mathrm{SD}$ ) in control animals and decreased to $10 \pm 2.7 \mathrm{~cm} \mathrm{H}_{2} \mathrm{O}$ in control animals treated with surfactant $(p<0.01)$. The Beta $0.1 \times 2$ treatment decreased pressure requirements to $16.7 \pm 2.9 \mathrm{~cm} \mathrm{H}_{2} \mathrm{O}$ in the absence of surfactant ( $p<0.01$ versus control), and surfactant treatment of this group decreased pressure requirements to only $7.7 \pm 2.1 \mathrm{~cm}$ $\mathrm{H}_{2} \mathrm{O}$ (Fig. 1). The Beta $0.2 \times 1$ and Beta $0.1 \times 1$ groups were not different from the control group in either the absence or the presence of surfactant. The Beta $0.1 \times 2$ group required significantly lower pressures than did the other two corticosteroidtreated groups in the absence of surfactant $(p<0.01)$. The calculated compliance values demonstrated the same trends as did the peak pressure measurements. Surfactant treatment improved compliance more than 2 -fold in all treatment groups $(p$ $<0.01$ ), with the increase in the Beta $0.1 \times 2$ group treated with surfactant approaching significance relative to the surfactanttreated control group.

SatPC in alveolar wash and lung. The SatPC pool measured by alveolar wash after $30 \mathrm{~min}$ of ventilation was $0.28 \pm 0.09$ $\mu \mathrm{mol} / \mathrm{kg}$ (mean $\pm \mathrm{SD}$ ) in control animals not treated with surfactant (Fig. 2). The alveolar pool size in animals in the Beta $0.1 \times 2$ and Beta $0.2 \times 1$ groups had smaller surfactant pools at $0.19 \pm 0.09$ and $0.22 \pm 0.10 \mu \mathrm{mol} / \mathrm{kg}$, respectively, that were significantly less than that of the Beta $0.1 \times 1$ groups $(0.32 \pm$ $0.17 \mu \mathrm{mol} / \mathrm{kg})(p<0.05)$. Total lung SatPC decreased by $18 \%$ in the Beta $0.1 \times 2$ group relative to the control group, and there were no changes noted for the other groups.

Recovery of radiolabeled albumin. A significant surfactant effect on the percentage recovery of intravascular albumin in the total lung (alveolar wash plus lung tissue) after $30 \mathrm{~min}$ of ventilation was noted with a decrease in labeled albumin recovery from $4.4 \pm 1.9 \%$ to $1.8 \pm 0.8 \%$ with surfactant treatment of control animals (mean $\pm \mathrm{SD})(p<0.01)$ (Fig. 3). Although significant surfactant effects were seen in all groups, only the Beta $0.1 \times 2$ group demonstrated decreased albumin recoveries relative to the control group and the other corticosteroid-treated groups that were not treated with surfactant $(p<0.01)$. The effect of the Beta $0.1 \times 2$ alone was as large as the effect of surfactant treatments in the other groups. The labeled albumin recoveries in alveolar lavages had similar patterns of recoveries with one exception. As with the total lung, surfactant decreased recoveries and Beta $0.1 \times 2$ decreased recoveries relative to the control and Beta $0.1 \times 1$ groups $(p<0.01)$. However, the Beta $0.2 \times 1$ group had lower alveolar recoveries than did the control and Beta $0.1 \times 1$ groups $(p<0.01)$.

\section{DISCUSSION}

The major goal of this experiment was to try to dissociate lung maturation from the fetal growth retardation effects of corticosteroids in preterm rabbits. The fact that either direct fetal injections or maternal injections of corticosteroids in rats and rabbits causes growth retardation (3-8) means that maturational effects on the lung are not a specific targeted response of the lungs to the hormone treatment. Instead, this lung maturational response must be viewed as a global response affecting the whole fetus and as such is likely to represent a nonspecific stress response and not the specific maturational targeting of an organ. Thus, the concept that corticosteroids only trigger receptors on fetal lung fibroblasts and/or type II cells to induce surfactant lipid and protein components is much too simplistic when associated with growth retardation. We previously demonstrated equivalent lung maturational responses in rabbits at doses of maternal betamethasone of 0.05 to $0.4 \mathrm{mg} / \mathrm{kg}$ given 48 and 24 $h$ after delivery of the preterm rabbits (8). The higher doses caused higher fetal death rates but the magnitude of growth retardation and lung maturation did not change with dose. Lower doses had no effect on either growth or lung maturation (19).

In this experiment, the Beta $0.1 \times 2$ reproduced the previously 
Table 2. Description of animals*

\begin{tabular}{|c|c|c|c|c|c|c|}
\hline Group & Surfactant & $n$ & $\begin{array}{c}\text { Body weight } \dagger \\
\mathrm{g}\end{array}$ & $\begin{array}{c}\text { Tidal volume } \\
(\mathrm{mL} / \mathrm{kg})\end{array}$ & $\mathrm{PCO}_{2}(\mathrm{kPa}) \ddagger$ & $\mathrm{pH}$ \\
\hline \multirow[t]{2}{*}{ Control } & - & 16 & $29.3 \pm 3.8$ & $8.0 \pm 0.4$ & $6.52 \pm 0.93$ & $7.18 \pm .12$ \\
\hline & + & 12 & $29.2 \pm 3.7$ & $8.1 \pm 0.7$ & $5.87 \pm 0.80$ & $7.21 \pm .14$ \\
\hline \multirow[t]{2}{*}{ Betamethasone $0.1 \times 2$} & - & 15 & $22.5 \pm 2.6$ & $8.4 \pm 0.6$ & $6.76 \pm 1.02$ & $7.15 \pm .17$ \\
\hline & + & 16 & $24.3 \pm 3.8$ & $8.2 \pm 1.2$ & $5.80 \pm 1.27$ & $7.23 \pm .18$ \\
\hline \multirow[t]{2}{*}{ Betamethasone $0.2 \times 1$} & - & 15 & $23.6 \pm 4.5$ & $8.2 \pm 0.4$ & $6.74 \pm 0.94$ & $7.15 \pm .15$ \\
\hline & + & 13 & $23.5 \pm 4.2$ & $8.6 \pm 1.0$ & $6.12 \pm 1.35$ & $7.21 \pm .19$ \\
\hline \multirow[t]{2}{*}{ Betamethasone $0.1 \times 1$} & - & 19 & $26.1 \pm 3.9$ & $8.2 \pm 0.4$ & $7.41 \pm 1.27$ & $7.08 \pm .12$ \\
\hline & + & 15 & $26.9 \pm 3.7$ & $8.2 \pm 1.0$ & $5.91 \pm 1.28$ & $7.19 \pm .13$ \\
\hline
\end{tabular}

$*$ Values given as mean $\pm \mathrm{SD}$.

$\dagger$ Body weight differences for combined \pm surfactant groups were control $>$ Beta $0.1 \times 1>$ Beta $0.1 \times 2$ and Beta $0.2 \times 1(p<0.01)$.

$\ddagger \mathrm{kPa} \times 7.55=\mathrm{mm} \mathrm{Hg}$.
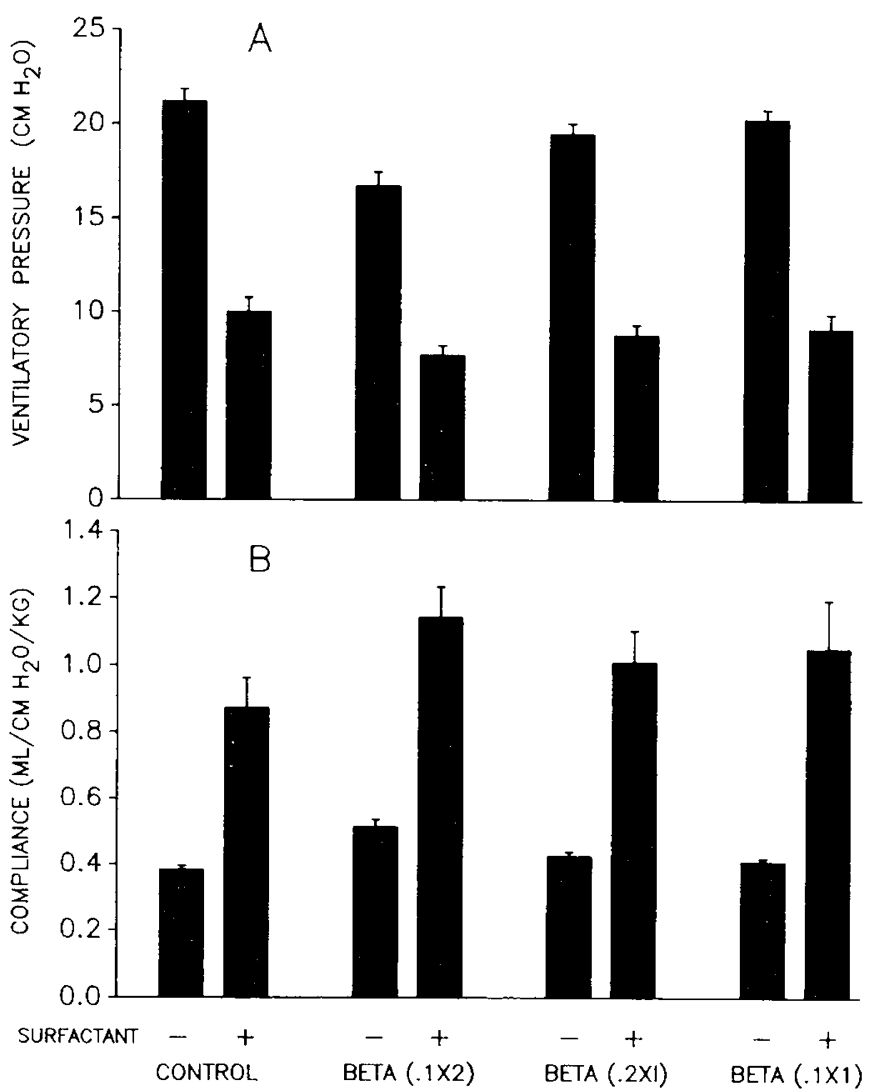

Fig. 1. Ventilatory pressures and compliances for preterm rabbits at $30 \mathrm{~min}$ of age, given as means \pm SEM. $A$, Ventilatory pressures were calculated as peak inspiratory pressures minus $3 \mathrm{~cm} \mathrm{H}_{2} \mathrm{O}$ positive end expiratory pressures. Surfactant decreased pressures in all groups $(p<$ 0.01 ). The Beta $0.1 \times 2$ group had lower pressure requirements than did the control group $(p<0.01)$. $B$, Compliance values increased with surfactant treatment in all groups $(p<0.01)$. One $\mathrm{mg}=2.13 \mu \mathrm{mol}$ betamethasone.

reported effects on both fetal growth and lung maturation $(8,20$, 21). The growth-retarded fetuses had lower alveolar surfactant SatPC pool sizes, lower ventilator pressure requirements, less pulmonary edema as measured by albumin recovery, and improved responses to surfactant treatments relative to the control animals. These same effects on lung maturation and fetal growth were previously reported with $0.05 \mathrm{mg} / \mathrm{kg}$ betamethasone given 24 and $48 \mathrm{~h}$ before delivery (total dose $0.1 \mathrm{mg} / \mathrm{kg}$ ) (8). In this experiment, Beta $0.1 \times 1$ caused less growth retardation, but there was no improvement in lung function detected, and the lung and alveolar SatPC pool sizes were unchanged from control

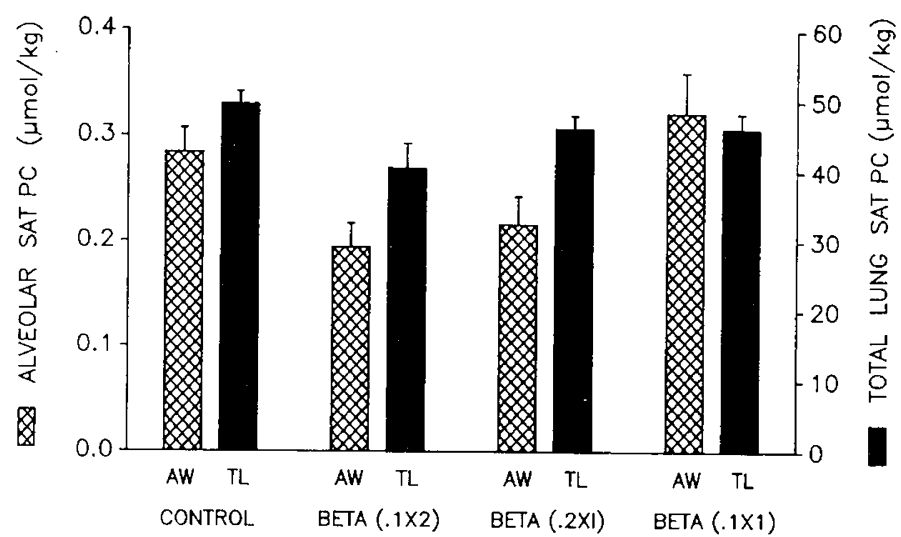

Fig. 2. SatPC pool sizes in the alveolar washes and total lung (sum of lung tissue plus alveolar washes, betamethasone SEM). The Beta $0.1 \times$ 2 and Beta $0.2 \times 1$ treatments decreased alveolar pool sizes relative to control and Beta $0.1 \times 1$ groups $(p<0.05)$. One $\mathrm{mg}=2.13 \mu \mathrm{mol}$ betamethasone.

values. Thus, we have found a dose of maternal corticosteroids that causes growth retardation but does not induce lung maturation. This observation is particularly troubling in terms of the concept of specific lung maturational effects of corticosteroids in this rabbit model. We thought that a fetal effect caused by corticosteroids sufficient to cause growth retardation should have stimulated lung maturation; however, this is not true. This result is consistent with the clinical observation that growth-retarded infants frequently have respiratory distress syndrome. Growth retardation at birth has not been noted after maternal corticosteroid treatments in the human, and no such effect would be anticipated given the short period of exposure relative to the length of gestation. Subsequent growth after birth could be altered, but such effects have not been detected despite careful follow-up (1).

The results with the Beta $0.2 \times 1$ dosing schedule make the point that total dose is not the critical variable. Rather, the timing and spacing of the dose is more important for lung maturation (27). With this dose, the degree of growth retardation was identical to that achieved in the Beta $0.1 \times 2$ group. Although there were not significant effects of Beta $0.2 \times 1$ on ventilation variables or SatPC pools, this corticosteroid dose decreased albumin recoveries in the lung relative to control animals but not to the degree noted for the Beta $0.1 \times 2$ dose. Therefore, growth retardation and maturation were again dissociated by this dosing schedule because severe growth retardation was accompanied by the single indication of maturation response of decreased lung edema. We also correlated the indicators of lung maturation with body weight using linear regressions within each group. 

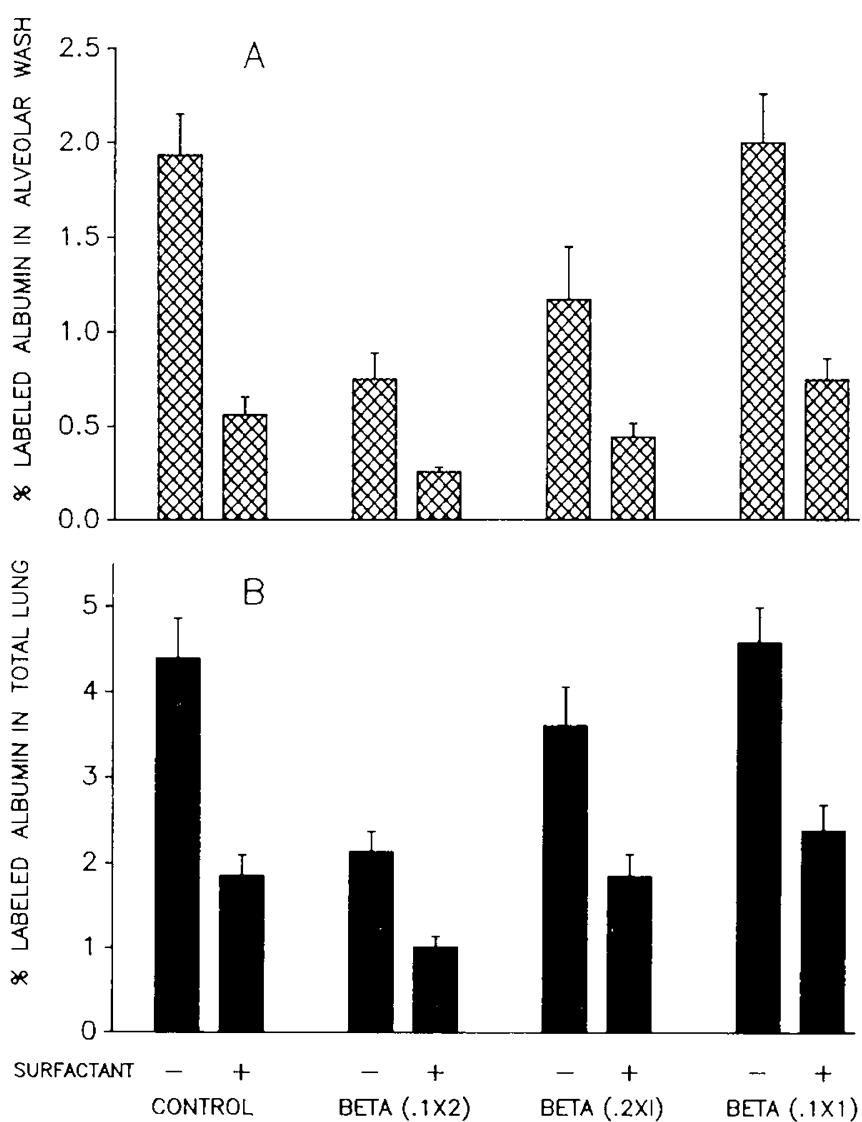

Fig. 3. Recovery of labeled albumin given by intravascular injection in alveolar washes and total lung calculated as alveolar wash plus lung tissue (mean $\pm \mathrm{SEM}$ ). $A$, Surfactant decreased alveolar albumin recoveries in all groups $(p<0.01)$. For the groups not treated with surfactant, albumin recoveries were Beta $0.1 \times 2<$ Beta $0.2 \times 1<$ Beta $0.1 \times 1$ and controls $(p<0.01)$, with a similar pattern of recoveries for surfactanttreated groups. $B$, Recoveries in total lung were decreased by surfactant in all groups $(p<0.01)$. Beta $0.1 \times 2$ caused a decreased recovery in the absence of surfactant relative to all other groups $(p<0.01)$. One $\mathrm{mg}=$ $2.13 \mu \mathrm{mol}$ betamethasone.

There were not strong correlations indicating that lung maturation was not associated with weight within each group.

These results of variable maturational responses depend critically on dosing schedule. We were unable to achieve maturational effects resulting in improved lung function with single doses of maternal corticosteroids $48 \mathrm{~h}$ before delivery of the preterm rabbits. There also was no effect elicited with surfactant treatments above those detected in control animals. This functional outcome contrasts with the demonstration of increased lung enzyme levels $24 \mathrm{~h}$ after a single dose of maternal corticosteroid in more immature fetal rabbits $(28,29)$. Oulton et al. (27) used the different dosing strategy of giving a single dose of intraperitoneal cortisol to fetal rabbits followed by maternal thyrotropin releasing hormone to achieve maximal increases in surfactant pools. This use of multiple hormone therapies is now being evaluated in both animal models $(13,30)$ and in clinical trials (31). The maturational effects of corticosteroids in rabbits are not primarily on the surfactant system, inasmuch as alveolar SatPC pool sizes tend to decrease when they are measured after preterm delivery and a period of ventilation. Corticosteroids have multiple effects on the fetal lung structure that include increases in lung volumes (30), changes in matrix proteins (32), changes in lung rupture pressures (33), changes in the alveolar surfactant pool size-compliance response curves (34), and improved responses to surfactant treatments (20). These results are consistent with multiple effects of the corticosteroids on the fetus that are associated with growth retardation. We think that rodent and rabbit models for studies of the mechanism of lung maturation must be interpreted cautiously because of the association of growth retardation with corticosteroid treatments.

\section{REFERENCES}

1. Crowley P, Chalmers I, Keirse M 1990 The effects of corticosteroid administration before preterm delivery: an overview of the evidence from controlled trials. Br J Obstet Gynaecol 97:11-25

2. Liggins GC 1969 Premature delivery of foetal lambs infused with glucocorticoids. J Endocrinol 45:515-523

3. Kotas RV, Avery ME 1971 Accelerated appearance of pulmonary surfactant in the fetal rabbit. J Appl Physiol 30:358-361

4. Wang NS, Kotas RV, Avery ME, Thurlbeck WM 1971 Accelerated appearance of osmiophilic bodies in fetal lungs following steroid injection. $\mathrm{J}$ Appl Physiol 30;362-365

5. Taeusch Jr HW, Avery ME, Sugg J 1972 Premature delivery without accelerated lung development in fetal lambs treated with long-acting methylprednisolone. Biol Neonate 20:85-92

6. Kauffman S 1977 Acceleration of canalicular development in lungs of fetal mice exposed transplacentally to dexamethasone. Lab Invest 36:395-401

7. Navarro HA, Kudlacz KM, Eylers JP, Slotkin TA 1989 Prenatal dexamethasone administration disrupts the pattern of cellular development in rat lung. Teratology 40:433-438

8. Rider E, Jobe A, Ikegami M, Yamada T, Seidner S 1990 Antenatal betamethasone dose effects in 27 day gestation preterm rabbits. $\mathrm{J}$ Appl Physiol 68:1134-1141

9. Epstein MF, Farrell PM, Sparks JW, Pepe G, Driscoll SG, Chez RA 1977 Maternal betamethasone and fetal growth and development in the monkey. Am J Obstet Gynecol 127:261-263

10. Platzker ACG, Kitterman JA, Mescher EJ, Clements JA, Tooley WH 1975 Surfactant in the lung and tracheal fluid of the fetal lamb and acceleration of its appearance by dexamethasone. Pediatrics 56:554-561

11. Warburton D, Parton L, Buckley S, Cosico L, Enns G, Saluna T 1988 Combined effects of corticosteroid, thyroid hormones, and $\beta$-agonist on surfactant, pulmonary mechanics, and $\beta$-receptor binding in fetal lamb lung. Pediatr Res 24:166-170

12. Kendall JZ, Lakritz J, Plopper CG, Richards GE, Randall GCB, Nagamani M, Weir J 1990 The effects of hydrocortisone on lung structure in fetal lambs. J Dev Physiol 13:165-172

13. Liggins GC, Schellenberg JC, Manzai M, Kitterman JA, Lee CCH 1988 Synergism of cortisol and thyrotropin releasing hormone on lung maturation in fetal sheep. J Appl Physiol 65:1880-1884

14. Phelps DS, Floros J 1991 Dexamethasone in vivo raises surfactant protein B mRNA in alveolar and bronchiolar epithelium. Am J Physiol 260:L146L152

15. Schellhase DE, Shannon JM 1991 Effects of maternal dexamethasone on expression of SP-A, SP-B and SP-C in the fetal rat lung. Am $J$ Respir Cell Mol Biol 4:304-412

16. Chaudhary KC, Nijjar MS 1984 Effects of dexamethasone administration to pregnant rats on adenylate cyclase and cyclic AMP phosphodiesterase activities in the maternal and fetal lungs. Biol Nconate 45:188-196

17. Post M 1987 Maternal administration of dexamethasone stimulates cholinephosphate cytidylyltransferase in fetal type II cells. Biochem J 241:291-296

18. Frank L, Roberts RJ 1979 Effects of low-dose prenatal corticosteroid administration on the premature rat. Biol Neonate $36: 1-9$

19. Tabor BL, Rider ED, Ikegami M, Jobe AH, Lewis JF 1991 Dose effects of antenatal corticosteroids for induction of lung maturation in preterm rabbits. Am J Obstet Gynecol 164:675-681

20. Ikegami M, Jobe A, Seidner S, Yamada $\Upsilon 1989$ Gestational effects of corticosteroids and surfactant in ventilated rabbits. Pediatr Res 25:32-37

21. Jobe A, Ikegami M, Glatz T, Yoshida Y, Diakomanolis E, Padbury J 1981 The duration and characteristics of treatment of premature lambs with natural surfactant. J Clin Invest 67:370-375

22. Ikegami M, Berry D, ElKady T, Pettenazzo A, Seidner S, Jobe A 1987 Corticosteroids and surfactant change lung function and protein leaks in the lungs of ventilated premature rabbits. J Clin Invest 79:1371-1378

23. Rider ED, Jobe AH, Ikegami M, Sun B 1992 Different ventilation strategies alter surfactant responses in preterm rabbits. J Appl Physiol 73:2089-2096

24. Jobe A, Jacobs H, Ikegami M, Berry D 1985 Lung protein leaks in ventilated lambs: effects of gestational age. J Appl Physiol 58:1246-1251

25. Mason RJ, Hellenbogen J, Clements JA 1976 Isolation of disaturated phosphatidylcholine with osmium tetroxide. J Lipid Res 17:281-284

26. Bartlett GR 1959 Phosphorus assay in column chromatography. J Biol Chem 234:466-468

27. Oulton M, Rasmusson MG, Yoon RY, Fraser M 1989 Gestation-dependent effects of the combined treatment of glucocorticoids and thyrotropin-releas- 
ing hormone on surfactant production by fetal rabbit lung. Am J Obstet Gynecol 160:961-967

28. Rooney SA, Gross I, Gassenheimer LN, Motoyama EK 1975 Stimulation of glycerophosphate phosphatidyltransferase activity in fetal rabbit lung by cortisol administration. Biochim Biophys Acta 398:433-441

29. Possmayer F, Casola P, Chan F, Hill S, Metcalfe IL, Stewart-Dehaan PJ, Wong

T, Las Heras J, Gammal EB, Harding PGR 1979 Glucocorticoid induction of pulmonary maturation in the rabbit fetus. Biochim Biophys Acta 574:197211

30. Ikegami M, Polk D, Tabor B, Lewis J, Yamada T, Jobe A 1991 Corticosteroid and thyrotropin-releasing hormone effects on preterm sheep lung function. J Appl Physiol 70:2268-2278
31. Ballard RA, Ballard PL, Creasy RH, Padbury J, Polk DH, Bracken M, Moya FR, Gross I 1992 Respiratory disease in very low birth weight infants after prenatal treatment with TRH. Lancet 339:510-515

32. Beck JC, Mitzner W, Johnson WC, Hutchins GM, Foidart J-M, London WT, Palmer AE, Scott R 1981 Betamethasone and the rhesus fetus: effect on lung morphometry and connective tissue. Pediatr Res 15:235-240

33. ElKady T, Jobe A 1987 Corticosteroids and surfactant increase lung volumes and decrease rupture pressures of preterm rabbit lungs. J Appl Physiol 63:1616-1621

34. Seidner S, Pettenazzo A, Ikegami M, Jobe A 1988 Potentiation of dose response relationships of surfactant in preterm rabbits following maternal corticosteroid treatments. J Appl Physiol 64:2366-237 